\title{
Randomised placebo-controlled trial of inhaled sodium cromoglycate in 1-4-year-old children with moderate asthma
}

\author{
M J A Tasche, J C van der Wouden, J H J M Uijen, B P Ponsioen, R M D Bernsen, L W A van Suijlekom-Smit, \\ $J C$ de Jongste
}

\begin{abstract}
Summary
Background Inhalation therapy with sodium cromoglycate is recommended as the first-line prophylactic treatment for moderate asthma in children. The availability of spacer devices with face-masks has extended the applicability of metered-dose inhalers to younger children. We studied the feasibility and effects of this therapy compared with placebo in children aged 1-4 years.
\end{abstract}

Methods 218 children aged 1-4 years with moderate asthma were recruited through 151 general practitioners between March, 1995, and March, 1996. They were randomly assigned sodium cromoglycate $(10 \mathrm{mg}$ three times daily) or placebo, given by inhaler with spacer device and face-mask for 5 months. Rescue medication (ipratropium plus fenoterol aerosol) was available during the baseline period of 1 month and the intervention period. Parents completed a daily symptom-score list. The primary outcome measure was the proportion of symptomfree days in months 2 to 5 . Analysis was by both intention to treat and on treatment.

Findings 167 (77\%) children completed the trial. 131 (78\%) of these children used at least $80 \%$ of the recommended dose. Of the 51 children who stopped prematurely, 23 had difficulties with inhaled treatment. The mean proportion of symptom-free days for both groups was greater for the treatment period than for the baseline period $(95 \% \mathrm{Cl}$ for mean difference 5.1 to 17.5 cromoglycate, 11.9 to 23.3 placebo). However there were no differences between the sodium cromoglycate and placebo groups in the proportion of symptom-free days (mean 65.7 [SD 25.3] vs 64.3 [24.5]\%; 95\% Cl for difference -8.46 to 5.70 ) or in any other outcome measure.

Interpretation Our study in a general practice setting shows that inhalation therapy with a spacer device and face-mask is feasible in a majority of children below the age of 4 years. However, long-term prophylactic therapy with inhaled sodium cromoglycate is not more effective than placebo in this age-group.

Lancet 1997; 350: 1060-64

Department of General Practice (M J A Tasche MD,

J C van der Wouden PhD, J H J M Uijen MD, B P Ponsioen MD,

R M D Bernsen MSc), Department of Pediatrics

( $L$ W A van Suijlekom-Smit MD), and Division of Pediatric

Respiratory Medicine (Prof J C de Jongste MD), Erasmus University and Academic Hospital Rotterdam/Sophia Children's Hospital, Rotterdam, Netherlands

Correspondence to: Dr M J A Tasche, Department of General Practice (Room Ff321), Erasmus University Rotterdam, PO Box 1738, 3000 DR Rotterdam, Netherlands

\section{Introduction}

Respiratory diseases are an important cause of morbidity in young children. ${ }^{1}$ The prevalence of asthma and persistent wheeze in children aged 1-4 years is between $10 \%$ and $20 \%,,^{2,3}$ the variation apparently the result of differing definitions. National and international consensus reports recommend sodium cromoglycate as prophylactic agent of first choice in young children with moderate asthma. ${ }^{4,5}$

Sodium cromoglycate is a safe prophylactic drug that is widely used to treat asthma in children, although its mechanism of action is not fully understood. ${ }^{67}$ Despite widespread use, the effect of inhaled sodium cromoglycate in very young children with moderate asthma has hardly been studied. Several placebocontrolled trials ${ }^{8-18}$ have been reported but most were hospital-based, studied patients with severe asthma, had follow-up periods shorter than 10 weeks, and studied medication inhaled by nebulisation. Six of these studies showed improvement of symptoms in comparison with placebo, ${ }^{8-13}$ but in five sodium cromoglycate was no better than placebo. ${ }^{14-18}$

Data on the prescription of antiasthma drugs in primary and secondary care show a trend of decreasing use of sodium cromoglycate and increasing use of inhaled steroids. ${ }^{19}$ Because there is no convincing evidence that inhaled steroids, even in daily doses of less than $400 \mu \mathrm{g}$, are without side-effects in the long-term treatment of young children, there is still a potential role for sodium cromoglycate for treating moderate asthma. ${ }^{20,21}$ König and Shaffer ${ }^{22}$ suggested in 1996 (based on a retrospective study) that treatment with sodium cromoglycate improves the long-term prognosis of childhood asthma.

Nebulisation in young children is tedious and timeconsuming and therefore used mainly in severe asthma. The availability of spacer devices with face-masks has extended the use of metered-dose inhalers to children of preschool age. In the Netherlands most children with moderate asthma are treated by general practitioners (GPs). Little is known, however, about the feasibility of and compliance with long-term prophylactic therapy when medication is inhaled through a spacer device and face-mask at home in young children with moderate asthma. We undertook a study to investigate these issues in a comparison of inhaled sodium cromoglycate and placebo.

\section{Methods}

Children aged 1-4 years who had previously been on medication specifically prescribed for respiratory problems (oral or inhaled bronchodilators, oral or inhaled steroids, sodium cromoglycate or nedocromil sodium [though the latter is rarely used in young children], ketotifen, deptropine) were selected from the computer files of 151 GPs in the Rotterdam area. On 
behalf of the GP, we sent a postal questionnaire to each child's parents, enquiring about the child's symptoms and current antiasthma medication. We defined moderate asthma as one or more of: more than 12 episodes of coughing, wheeze, or dyspnoea during the past year; use of antiasthma medication; and at least two of the following three during the past monthcoughing, wheezing, or dyspnoea more than once a week; interference of respiratory symptoms with daily activities; and interference of symptoms with sleep. Children who had been prescribed oral or inhaled steroids or who had been admitted to hospital for acute asthma in the past were classified as having severe asthma. With the GP's approval, the parents of each child classified as having moderate asthma were asked to join the study. Exclusion criteria were congenital disorders and language difficulties (inability to speak Dutch adequately).

Children were enrolled from March, 1995, to March, 1996, to make sure the trial period included all four seasons. During the first visit, the research physician recorded the child's medical history and condition at that time, examined the respiratory tract, ears, nose, and throat, and measured height and weight. The parents gave written informed consent

Enrolled children entered a baseline period of 4 weeks, during which only rescue medication (ipratropium plus fenoterol aerosol; Berodual, Boehringer Ingelheim, Germany) was available. If the child was already using prophylactic medication, the baseline period was preceded by a washout period of 3 weeks.

At the end of the baseline period, the children were randomly assigned inhalation therapy with either sodium cromoglycate or placebo, $10 \mathrm{mg}$ (two puffs) three times daily with a spacer device and face-mask (Aerochamber, Boehringer Ingelheim). Study medication (sodium cromoglycate and placebo) was prepared by Fisons plc, Loughborough, UK. We randomised in blocks of six patients and stratified for age, assigning blocks by years of age $(1,2$, and 3 years). Parents were provided with rescue medication to be used in case of exacerbation. The study medication was given for 5 months.

For use of the inhaler, parents were instructed to shake the cannister and spray it into the spacer twice, with an interval of $5 \mathrm{~s}$, fitting the facemask tightly around the child's nose and mouth as from the first actuation, and to have the child breathe normally for $30 \mathrm{~s}$. We instructed the parents to rinse the spacer device with tap water and allow it to drain, no more than once a week.

During the trial, each child was visited at home once a month by a research nurse. During the visit the nurse checked the inhalation technique with the parents, and asked about respiratory or other symptoms, side-effects, difficulties with the spacer device, and visits to the GP or other clinician. Throughout the study, treatment allocation was concealed from parents, patients, GPs, the research physician, and nurses.

Since there is no suitable method of measuring lung function in this age-group at home, symptoms are the most relevant measure of the effect of treatment. ${ }^{23}$ We asked parents to fill in a daily symptom-score list (panel) to record their child's asthma symptoms, limitation of activity during the day and at night, and use of trial and rescue medication.

The primary outcome measure was the proportion of symptom-free days in months $2-5$ of the intervention period. Other outcome measures were number of symptoms (possible scores $0-4$ per day), use of rescue medication, loss of participants during the trial, need for additional medication, need for GP visits, referrals to secondary care, and parent's guess about the type of treatment. We asked parents of children withdrawn during the trial to continue filling in the daily symptom-score list for the remainder of the trial period.

All GPs were advised to prescribe a short course of oral prednisone if asthma symptoms could not be controlled by trial or rescue medication. Reasons for withdrawal from the trial were: more than one exacerbation that had to be treated with oral prednisone; prescription of long-term therapy with inhaled steroids; and hospital admission for exacerbation, adenoidectomy, or tonsillectomy.

\section{Questions for daily symptom-score list}

Did you notice your child coughing or wheezing last night?

Was your child awake because of

coughing or wheezing last night?

Did you notice coughing, wheezing,

or shortness of breath today?

Did these airway symptoms interfere

with the activities of your child?

How often did your child inhale trial

medication today?

How often did your child inhale

Berodual today?
Yes/no

Yes/no

Yes/no

Yes/no

$0 / 1 / 2 / 3$ times

$0 / 1 / 2 / 3$ or more times
At the beginning of the trial we weighed a random sample of full cannisters of study medication. After the trial all cannisters were weighed on the same balance (Mettler AE 260 deltarange, Tiel, Netherlands) to assess compliance.

A pilot study showed that children with moderate asthma had on average 1 symptom-free day in 2 , as in a study by Cogswell and colleagues. ${ }^{\text {T }}$ To detect a difference in proportion of symptom-free days between cromoglycate and placebo of $20 \%$ at a significance level of 0.05 and a power of $80 \%$, assuming an $\mathrm{SD}$ of $32 \%$, as calculated from baseline symptom scores, 40 children per group would be needed. We decided to enrol more children to enable the analysis of subgroups.

The strategy for data analysis was written before the randomisation code was broken. Analyses were done by both intention to treat and on treatment. We analysed the main efficacy variable - ie, proportion of symptom-free days-by a repeated-measures analysis of covariance. This model involved both the mean response over the treatment period (to detect a possible treatment effect) and a linear trend (to detect a possible treatment by time interaction) of dependent variables. Independent variables were test medication (cromoglycate,

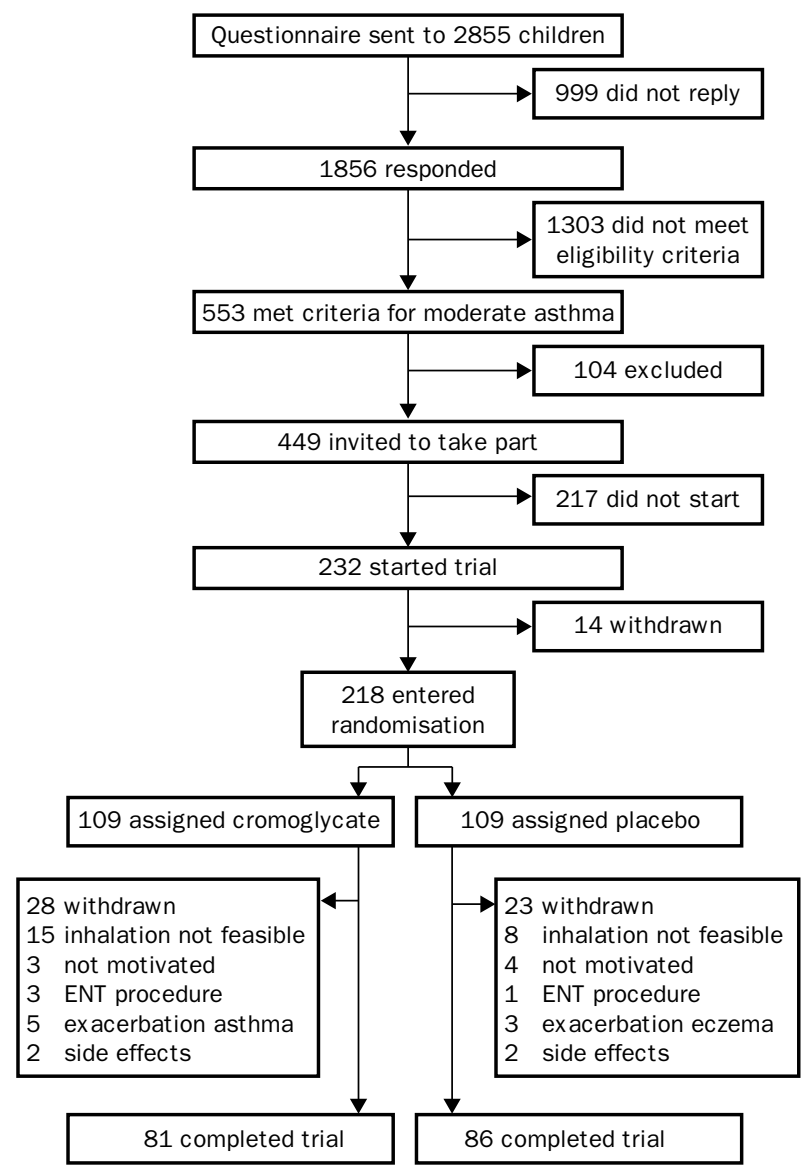

Figure 1: Trial profile 


\begin{tabular}{|c|c|c|}
\hline & $\begin{array}{l}\text { Cromoglycate } \\
(n=109)\end{array}$ & $\begin{array}{l}\text { Placebo } \\
(n=109)\end{array}$ \\
\hline Mean (SD) age in years & $2.6(0.9)$ & $2.5(0.8)$ \\
\hline \multicolumn{3}{|l|}{ Number aged at entry } \\
\hline $12-23$ months & $34(31 \%)$ & $31(28 \%)$ \\
\hline 24-35 months & $32(29 \%)$ & $36(33 \%)$ \\
\hline $26-48$ months & $43(39 \%)$ & $42(39 \%)$ \\
\hline Male/female & $58 / 51$ & $64 / 45$ \\
\hline \multicolumn{3}{|l|}{ Medical history } \\
\hline $\begin{array}{l}\text { Mean (SD)\% symptom-free days during } \\
\text { baseline period }\end{array}$ & $56 \cdot 5(31 \cdot 3)$ & $47 \cdot 6(33 \cdot 2)$ \\
\hline Perceived influence of season & $60(55 \%)$ & $57(52 \%)$ \\
\hline Eczema & $61(56 \%)$ & $63(58 \%)$ \\
\hline Food allergy & $48(44 \%)$ & $47(43 \%)$ \\
\hline Asthma also induced by exercise & $36(33 \%)$ & $36(33 \%)$ \\
\hline Experience with inhalation therapy & $40(37 \%)$ & $36(33 \%)$ \\
\hline Family history of asthma & $72(66 \%)$ & $58(53 \%)$ \\
\hline \multicolumn{3}{|l|}{ Family characteristics } \\
\hline Parental smoking & $73(67 \%)$ & $58(53 \%)$ \\
\hline Mean (SD) age mother on day of birth & $28.7(4.5)$ & $28 \cdot 7(4 \cdot 1)$ \\
\hline Of non-Dutch origin & $5(5 \%)$ & $9(8 \%)$ \\
\hline In day care & $43(39 \%)$ & $49(45 \%)$ \\
\hline Mean (SD) position in birth order & $1.85(0.89)$ & $1.94(0.83)$ \\
\hline Education mother low* & $66(61 \%)$ & $71(65 \%)$ \\
\hline Education father low* & $44(40 \%)$ & $41(38 \%)$ \\
\hline \multicolumn{3}{|l|}{ Anthropometry } \\
\hline Mean (SD) length $(\mathrm{cm})$ & $93(9)$ & $93(8)$ \\
\hline Mean (SD) weight (kg) & $15 \cdot 9(3 \cdot 1)$ & $15 \cdot 5(2 \cdot 7)$ \\
\hline
\end{tabular}

Table 1: Characteristics of treatment groups at start of trial

placebo); sex; seasonal influence (autumn+winter/spring+ summer); and smoking by parents; food allergy; eczema; experience with inhalation therapy; and positive family history (all no/yes). Age (months) and baseline value of percentage symptom-free days were used as covariates. Because of a possible violation of the normality assumption, we did the same analysis on arcsinsquare-root-transformed outcome data. ${ }^{24}$ Separate analyses of subgroups were done for sex, age, and season. Differences in side-effects and secondary effect measures were tested by $\chi^{2}$ test, $t$ test, or Fisher's exact test (two-sided).

The Medical Ethics Committee of Erasmus University Rotterdam/Academic Hospital Rotterdam approved the trial.

\section{Results}

2855 children who had previously been on specific respiratory medication were selected from 151 general practices (figure 1). The overall response rate to the questionnaire was $65 \%$. Respondents and nonrespondents were similar in terms of age and medication prescribed. 553 children ( $30 \%$ of respondents) met our inclusion criteria for moderate asthma. 104 were not invited to take part, because the GP did not approve of inclusion (mostly because of social circumstances, 20), because we could not contact the parents (43), or because of congenital disorders (three), language difficulties (11), corticosteroid therapy (21), or an adenoidectomy/tonsillectomy planned in the near future (six). 449 children were invited to take part.

Between March, 1995, and March, 1996, 232 children ( $42 \%$ of those with moderate asthma) entered the baseline period or washout period. 217 children did not start the trial; the parents of 72 children refused to participate because they expected feasibility problems, 109 did not want changes in therapy, 27 did not want any research, and nine refused for unknown reasons. A further 14 children were withdrawn during the washout or baseline period because the inhalation procedure was not feasible (three), the child had an exacerbation of asthma (five), an ear, nose, and throat procedure was planned (two), or other reasons (four). 218 children

\begin{tabular}{|c|c|c|}
\hline & $\begin{array}{l}\text { Cromoglycate } \\
\text { (n=109) }\end{array}$ & $\begin{array}{l}\text { Placebo } \\
\text { (n=109) }\end{array}$ \\
\hline No side-effects & $69(63 \%)$ & $73(67 \%)$ \\
\hline \multicolumn{3}{|l|}{ Behaviour } \\
\hline More active & $6(6 \%)$ & $12(11 \%)$ \\
\hline More sleepy & $8(7 \%)$ & $5(5 \%)$ \\
\hline \multicolumn{3}{|l|}{ Skin } \\
\hline Eczema around nose and mouth & $5(5 \%)$ & 0 \\
\hline Other & $7(6 \%)$ & $8(7 \%)$ \\
\hline Cough after inhalation & $9(8 \%)$ & $1(1 \%)$ \\
\hline Gastrointestinal & $5(5 \%)$ & $6(6 \%)$ \\
\hline Other & $5(5 \%)$ & $4(4 \%)$ \\
\hline
\end{tabular}

Table 2: Side-effects

remained, of whom 109 were assigned sodium cromoglycate and 109 placebo.

The groups were similar except for baseline symptom score (table 1). During the trial period 51 children (23\%; 28 in cromoglycate group, 23 in placebo group) were withdrawn (figure 1). 23 (37\%) of the 1-year-olds left the trial prematurely, compared with 11 (16\%) 2-yearolds, and $17(19 \%)$ 3-year-olds. The main reason for withdrawal of 1-year-olds was the difficulty parents and children experienced in using the spacer device. Of the children who stopped prematurely, the parents of 38 (23 sodium cromoglycate group, 15 placebo group) kept recording symptoms, although 14 of them registered the daily symptoms for only part of the remainder of the trial period. 13 children (five sodium cromoglycate group, eight placebo group) were lost to follow-up. 167 (77\%) children completed the trial.

Parents of $40(37 \%)$ children in the cromoglycate group and $33(30 \%)$ children in the placebo group reported side-effects (table 2). No serious side-effects were reported for either group by parents or GPs. Eczema around the place where the mask was applied occurred in five children in the cromoglycate group and none in the placebo group $(p=0.052)$. Nine children in the cromoglycate group and one in the placebo group had coughing after inhalation $(p=0.02)$. The frequencies of other side-effects were similar in the two groups.

We estimated compliance from the weights of the returned cannisters (mean for cromoglycate group 310 [SE 4] g, placebo group 311 [4] g). Of the children who completed the trial, $66(81 \%)$ in the cromoglycate group and $65(76 \%)$ in the placebo group used more than $80 \%$ of the recommended dose $(\mathrm{p}=0 \cdot 35)$.

Averaged over months 2-5, the proportion of symptom-free days in the cromoglycate group was $65 \cdot 7 \%$ (SD 25.3), compared with $64 \cdot 3 \%(24 \cdot 5)$ in the placebo group $(95 \%$ CI for difference, placebo minus cromoglycate, $-8 \cdot 46$ to $5 \cdot 70$ ). In both groups of children, the proportion of symptom-free days improved significantly during treatment (paired $t$ test, $\mathrm{p}<0.01$; $95 \% \mathrm{CI}$, treatment minus baseline, cromoglycate $5 \cdot 1$ to $17 \cdot 5$, placebo 11.9 to $23 \cdot 3$ ). There was no significant difference in this increase between the groups (figure 2). The 95\% CI for the difference between placebo and sodium cromoglycate (percentage symptom-free days) adjusted for baseline value was $-4 \cdot 6$ to $7 \cdot 7$. Analysis of covariance revealed no significant treatment effect, significant treatment by time interaction, or influence of age, sex, eczema, familiarity with inhalation therapy, seasonal influence, or parental smoking on the overall proportion of symptom-free days. Baseline values were predictive of outcome. Analysis of the transformed data 

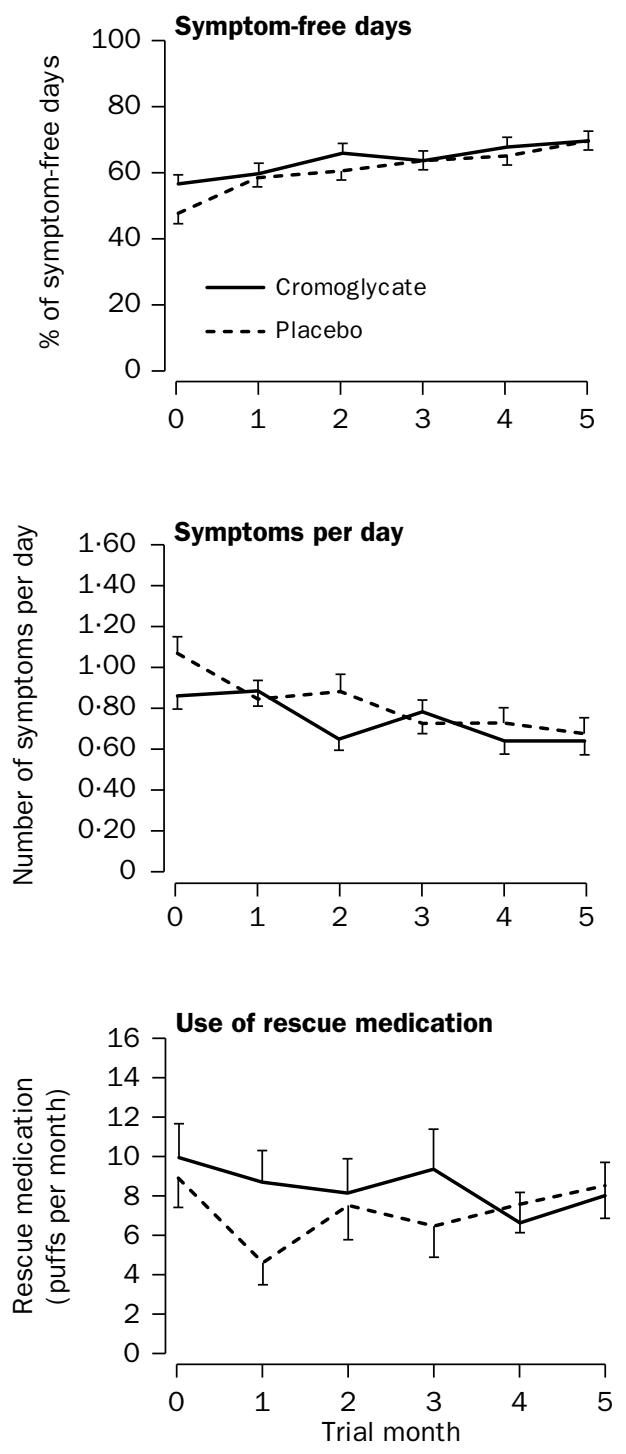

Figure 2: Mean (SE) proportion of symptom-free days, number of symptoms per day, and use of rescue medication

gave similar results. On-treatment analysis was done by repeating the tests only with children who had used more than $80 \%$ of the prescribed medication (66 cromoglycate group, 65 placebo group). We could not find any significant differences in outcome $(95 \%$ CI of difference between placebo and cromoglycate $-8 \cdot 21$ to $6 \cdot 41$ ).

The number of symptoms per day and use of rescue medication per month showed no significant differences between the treatment groups (figure 2). During the trial, parents of children in the cromoglycate group reported 368 episodes of illness, often with respiratory symptoms (164 episodes in 83 children). Parents of children in the placebo group reported 362 episodes of illness, $181(50 \%)$ with respiratory symptoms (88 children). 35 children in the cromoglycate group were taken to their GPs about asthma (61 visits) compared with 47 children (85 visits) in the placebo group $(p=0 \cdot 14)$. Additional medication was used in 29 and 35 children in the cromoglycate and placebo groups, respectively: antibiotics (13 vs 21), oral steroids (eight in each group), inhaled steroids (three $v$ five), deptropine (five $v s$ six), promethazine (three $v s$ seven), salbutamol (six $v s$ one), and ketotifen (three $v s$ one).

Growth, both linear and in weight, was similar in the two treatment groups during the trial.

$29 \%$ of parents of children in the cromoglycate group guessed the treatment correctly, whereas $37 \%$ of them thought their child had received placebo. In the placebo group, $30 \%$ of parents guessed the type of treatment correctly, and $33 \%$ thought their child had received cromoglycate. The remaining parents did not know.

\section{Discussion}

This study of long-term prophylactic inhalation therapy with a spacer device and face mask in 1-4-year-old children with moderate asthma showed that the treatment is feasible at home for such children $-77 \%$ of the children in our trial used an inhaler for 5 months, and $78 \%$ of users took at least $80 \%$ of the recommended dose. Of those who stopped prematurely, $45 \%$ had difficulty in using the inhaler, particularly the 1-yearolds. There were no differences in feasibility and compliance between the treatment groups. By contrast, Gibson and colleagues ${ }^{25}$ reported poor compliance in a 2 -month observational study in young children attending a paediatric respiratory clinic. In a study to assess compliance among adults receiving regular pulmonary medication in a general-practice setting, ${ }^{26}$ Dekker and colleagues could classify only $30 \%$ of the patients as compliant. We think that our better results could be explained by a selection bias of motivated parents and the intensive monitoring by the research nurses.

Both groups improved significantly in the proportion of symptom-free days. This finding can be explained by the placebo effect and the personal supervision associated with a clinical trial, as found previously in many trials on asthma in children.

The two groups did not differ in proportion of symptom-free days. We could not identify subgroups of children whose response to cromoglycate was influenced by age, sex, positive family history, atopic history, season, or smoking habits of the parents. GellerBernstein and Levin ${ }^{11}$ found an effect of cromoglycate in children aged 12 months and older, whereas no effect was seen in children below this age.

Notable side-effects of inhalation of sodium cromoglycate were cough directly after inhalation and eczema around the mouth. The first is well known, the latter was found previously in one of 29 children. ${ }^{15}$

The lack of benefit from treatment with sodium cromoglycate in this trial may have resulted from the spacer device we used. Several studies have shown a higher retainment of medication in this than in other spacer devices, ${ }^{27-29}$ so perhaps the dose of sodium cromoglycate reaching the lungs was inadequate in our trial. On the other hand, other studies have shown satisfactory drug delivery with this device in children. $^{30,31}$

There are few published data on assessment and monitoring of early childhood asthma, probably because wheezing disorders in young children are ill-defined. The limiting factor is our ability to measure the disorder itself. Most clinical measurement schemes are based on symptom assessment, even though symptoms are nonspecific and poorly defined, and scoring systems have not been adequately evaluated. ${ }^{32}$ However, since symptoms are directly related to the burden of disease, we question whether other, more objective, measures of morbidity 
would be superior.

We do not think the group size limits our conclusions. We can infer from the $95 \%$ CI that the difference between sodium cromoglycate and placebo, if any, is of no clinical importance.

We conclude, therefore, that inhalation therapy three times daily with a spacer device in young children with moderate asthma is feasible, but that treatment with sodium cromoglycate via the Aerochamber is no more effective than placebo. We could not show any benefit of sodium cromoglycate treatment that balances the effort and cost of this therapy. Therefore we support the intentions of national and international guidelines committees to withdraw the recommendation of sodium cromoglycate as the first choice in first-line inhaled prophylactic asthma treatment. ${ }^{33}$

\section{Contributors}

M J A Tasche executed and coordinated the study. J C van der Wouden supervised the study and with J H J M Uijen and B P Ponsioen was responsible for the design. R M D Bernsen carried out the main analyses. L W A van Suijlekom-Smit and J C de Jongste advised on the study design and interpretation of data. All the authors contributed to the writing of the paper.

\section{Acknowledgments}

This study was funded by the Netherlands Asthma Foundation (grant 93.37). We thank the parents, children, and GPs who took part; Fisons for providing the study medication and its preparation, Boehringer Ingelheim for providing the rescue medication and the Aerochambers; M J van Huuksloot, F Bischoff, and P D de Jonge for fieldwork; and Th Stijnen for statistical advice.

\section{References}

1 McCormick A, Fleming D, Charlton J. Morbidity statistics from general practice: fourth national study, 1991-1992. London: HMSO, 1995.

2 Luyt DK, Burton PR, Simpson H. Epidemiological study of wheeze, doctor diagnosed asthma, and cough in preschool children in Leicestershire. BMF 1993; 306; 1386-90.

3 Anderson HR, Pottier AC, Strachan DP. Asthma from birth to age 23: incidence and relation to prior and concurrent atopic disease. Thorax 1992; 47: 537-42.

4 British Thoracic Society and others. Guidelines for the management of asthma: a summary. BMF 1993; 306: 776-82.

5 Dirksen WJ, Geyer RMM, De Haan M, et al. NHG-standard Astma bij Kinderen. Huisarts en Wetenschap 1992; 35: 355-59.

6 Zeffren BS, Windom HH, Bahna SL. Modern treatment of asthma in children. Adv Pediatr 1996; 43: 423-68.

7 Hoag JE, McFadden ER. Long-term effect of cromolyn sodium on nonspecific bronchial hyperresponsiveness: a review. Ann Allergy 1991; 66; 53-63.

8 Yuksel B, Greenough A. Inhaled sodium cromoglycate for pre-term children with respiratory symptoms at follow-up. Respir Med 1992; 86: $131-34$.

9 Cogswell JJ, Simpkiss MJ. Nebulised sodium cromoglycate in recurrently wheezy preschool children. Arch Dis Child 1985; 60: 736-38.

10 Miraglia del Giudici M, Capristo A, Maiello N, Apuzzo G. Nebulized sodium cromoglycate for the treatment of asthma in children under five years of age. Mod Probl Paediatr 1982; 21; 122-27.

11 Geller-Bernstein C, Levin S. Nebulised sodium cromoglycate in the treatment of wheezy bronchitis in infants and young children. Respiration 1982; 43: 294-98.

12 Glass J, Archer LN, Adams W, Simpson H. Nebulised cromoglycate, theophylline, and placebo in preschool asthmatic children. Arch Dis Child 1981; 56; 648-51.

13 Hiller EJ, Milner AD, Lenney W. Nebulized sodium cromoglycate in young asthmatic children. Arch Dis Child 1977; 52; 875-76.

14 Furfaro S, Spier S, Drblik SP, Turgeon JP, Robert M. Efficacy of cromoglycate in persistently wheezing infants. Arch Dis Child 1994; 71: 331-34.

15 Bertelsen A, Andersen JB, Busch P, et al. Nebulised sodium cromoglycate in the treatment of wheezy bronchitis. Allergy 1986; 41; 266-70.

16 Henry RL, Hiller EJ, Milner AD, Hodges IGC, Stokes GM. Nebulised ipratropium and sodium cromoglycate in the first two years of life. Arch Dis Child 1984; 59; 54-57.

17 Varsano I, Mukamel M, Shuper A, Volovitz B, Shrem M, Jaber L. The efficiency of nebulization treatment with water compared to sodium cromoglycate in reducing upper respiratory infections in children. Helv Paediatr Acta 1983; 38; 335-39.

18 Lenney W, Milner AD. Nebulised sodium cromoglycate in the preschool wheezy child. Arch Dis Child 1978; 53; 474-76.

19 Warner JO. Review of prescribed treatment for children with asthma in 1990. BMF 1995; 311; 663-66.

20 Doull IJM, Donovan SJ, Wood PJ, Holg ate ST. Bloodspot cortisol in mild asthma: the effect of inhaled corticosteroids. Arch Dis Child 1995; 72: 321-24.

21 Bisgaard H, Pedersen S. Safety of treatment. Eur Respir f 1996; 8 (suppl): 28-34.

22 König P, Shaffer J. The effect of drug therapy on long-term outcome of childhood asthma: a possible preview of the international guidelines. F Allergy Clin Immunol 1996; 98: 1103-11.

23 Wilson N, van Bever H. Overall symptom measurement: which approach? Eur Respir F 1996; 21 (suppl): 8-11.

24 Rao CR. Linear statistical inference and its applications. London: Wiley; 1972: 427-32

25 Gibson NA, Ferguson AE, Aitchison TC, Paton JY. Compliance with inhaled asthma medication in preschool children. Thorax 1995; 50: 1274-79.

26 Dekker FW, Dieleman FE, Kaptein AA, Mulder JD. Compliance with pulmonary medication in general practice. Eur Respir F 1993; 6: 886-90.

27 Agertoft L, Pedersen S. Influence of spacer device on drug delivery to young children with asthma. Arch Dis Child 1994; 71: 217-20.

28 Bisgaard H, Anhoj J, Klug B, Berg E. A non electrostatic spacer for aerosol delivery. Arch Dis Child 1995; 73: 226-30.

29 Salmon B, Wilson NM, Silverman M. How much aerosol reaches the lungs of wheezy infants and toddlers? Arch Dis Child 1990; 65: 401-03.

30 Conner WT, Dolovich MB, Frame RA, Newhouse MT. Reliable salbutamol administration in 6- to 36-month-old children by means of a metered dose inhaler and Aerochamber with mask. Pediatr Pulmonol 1989; 6: 263-67.

31 Sly RM, Barbera JM, Middleton HB, Eby DM. Delivery of albuterol aerosol by aerochamber to young children. Ann Allergy 1988; 60; 403-06.

32 Silverman M. Outcome measures: an overview. Eur Respir F 1996; 9 (suppl): 1-3.

33 British asthma guidelines coordinating committee. British guidelines on asthma management: 1995 review and position statement commenting on the guidelines in the light of recent evidence. Thorax 1997; 52 (suppl): 1-21. 